\title{
Genetic and phenotypic parameters for test day milk yield of Sahiwal cattle in the semi-arid tropics
}

\author{
E. D. Ilatsia ${ }^{1,2}$, T. K. Muasya2, W. B. Muhuyi ${ }^{2}$ and A. K. Kahi ${ }^{1 \dagger}$ \\ ${ }^{1}$ Animal Breeding and Genetics Group, Department of Animal Sciences, Egerton University, PO Box 536, 20107 Njoro, Kenya; ${ }^{2}$ National Animal Husbandry Research \\ Centre, Kenya Agricultural Research Institute (KARI), PO Box 25, 20117 Naivasha, Kenya
}

(Received 4 January 2006; Accepted 7 November 2006)

\begin{abstract}
A total of 19376 test day (TD) milk yield records from the first three lactations of 1618 cows daughters of 162 sires were used to estimate genetic and phenotypic parameters and determine the relationship between daily milk yield and lactation milk yield in the Sahiwal cattle in Kenya. Variance components were estimated using animal models based on a derivative free restricted maximum likelihood procedure. Variance components were estimated using various univariate and multi-trait fixed regression test day models (TDM) that defined contemporary groups either based on the year-season of calving (YSCV) or on the year-season of TD milk sampling (YSTD). Variance components were influenced by CG which resulted in differences in heritability and repeatability estimates between TDM. Models considering YSTD resulted in higher additive genetic variances and lower residual variances compared with models in which YSCV was considered. Heritability estimates for daily yield ranged from 0.28 to 0.46 , 0.38 to 0.52 and 0.33 to 0.52 in the first, second and third lactation, respectively. In the first and second lactation, the heritability estimates were highest between TD 2 and TD 4. Genetic correlations among daily milk yields ranged from 0.41 to $0.93,0.50$ to 0.83 and 0.43 to 86 in the first, second and third lactation, respectively. The phenotypic correlations were correspondingly lower. Genetic correlations were different from unit when fitting multi-trait TDM. Therefore, a multiple trait model would be more ideal in determining the genetic merit of dairy sires and bulls based on daily yield records. Genetic and phenotypic correlations between daily yield and lactation yields were high and positive. Genetic correlations ranged from 0.84 to 0.99, 0.94 to 1.00 and 0.94 to 0.97 in the first, second and third lactations, respectively. The corresponding phenotypic correlation estimates ranged from 0.50 to $0.85,0.50$ to 0.83 and 0.53 to 0.87 . The high genetic correlation between daily yield and lactation yield imply that both traits are influenced by similar genes. Therefore daily yields records could be used in genetic evaluation in the Sahiwal cattle breeding programme.
\end{abstract}

Keywords: correlation, heritability, milk yield, Sahiwal, variance components.

\section{Introduction}

The Sahiwal breed is known to have the greatest potential for milk production, growth and reproductive efficiency in tropical environments compared with other Bos indicus breeds (Mwandotto, 1994; Dahlin et al., 1998; Khan et al., 1999; Muhuyi et al., 1999). Its ability to endure and produce in harsh environments coupled with its dual-purpose role has widened the distribution of this breed in tropical and subtropical countries. Among B. indicus breeds, the Sahiwal is the most frequently used in dairy crossbreeding in the tropics (Muhuyi, 1997; Kahi et al., 2000). The breed was introduced into Kenya from India and Pakistan in the late $1930 \mathrm{~s}$ after attempts to improve the Small East African Zebu through selection and breeding for milk

\footnotetext{
${ }^{\dagger}$ E-mail: a.kahi@incip.org
}

production showed low genetic progress. The National Sahiwal Stud (NSS) was established with objective of producing a dual-purpose breed suitable for pure breeding in semi-arid environments and crossbreeding for dairy production.

Selection within the Sahiwal herd is based on either standardised or total lactation milk yield. These yields are generated from sets of test day (TD) milk yield records made throughout the entire lactation length of an animal. Evaluation based on pooled TD milk yield does not satisfactorily account for effects that are specific to individual daily yield because contemporary groups are formed on year-season of calving (Jamrozik and Schaeffer, 1997; Swalve, 1998; Rekaya et al., 1999). Use of TD data would offer practical solutions in developing countries where 
there is lack of necessary infrastructure and resources required for milk recording throughout the lactation period.

Several test day models (TDM) for genetic evaluation exist and have been used in genetic evaluation of $B$. taurus dairy breeds in countries with well established breeding programmes characterised by official recording schemes with large data sets and accurate pedigree information (Vargas et al., 1998). Some of these countries have adopted the use of TDM in their routine genetic evaluation (Swalve, 2000; Jensen, 2001). The repeatability TDM proposed by Ptak and Schaeffer (1993) has been widely used. In this model, the curvilinear pattern of production is accounted for by fixed regressions of days in milk in the model. This model has been extended to a multiple trait TDM where TD records within lactation are considered as distinct traits. The multiple trait TDM has also been extended to a repeatability multiple trait TDM in which TD records in each lactation are considered as repeated observations and the lactations treated as separate traits (e.g. Reents et al., 1995a and b; Rekaya et al., 1999).

In developing countries, breeding programmes are characterised by inefficient recording systems and poor data collection, storage and processing procedures (Syrstad and Ruane, 1998; Kahi et al., 2004). Selection based on daily yield records would result in reduced cost of recording and maintaining cows and bulls with low breeding values (Schaeffer et al., 2000; Swalve, 2000). Genetic merit of animals can be predicted based on daily milk yield records from early lactations and cost reduced by less frequent recording as opposed to daily recording currently practised (Pander et al., 1992). However, use of TD data in genetic evaluation programmes requires accurate estimates of genetic and phenotypic parameters of specific daily milk yield records.

Information on estimates of genetic and phenotypic parameter and subsequent genetic evaluation of $B$. indicus cattle based on TD records is lacking. The challenge remains on which model to be used in this regard and therefore suitability of using various TDM under the existing economic and environmental circumstances has to be investigated. The objective of this study was to estimate genetic and phenotypic parameters for TD records of Sahiwal cattle using various fixed regression TDM.

\section{Material and methods}

\section{Data source}

Data were obtained from NSS, which is maintained by Kenya Agricultural Research Institute (KARI) at the National Animal Husbandry Research Centre, Naivasha. The centre is located to the east of Lake Naivasha in semi-arid rangelands in the Rift Valley Province at an altitude of 1829 to $2330 \mathrm{~m}$ above sea level. The average rainfall is $680 \mathrm{~mm}$ per annum. Rainfall distribution is bimodal with peaks in April and November. Temperatures varies from $8^{\circ} \mathrm{C}$ to $26^{\circ} \mathrm{C}$ while the relative humidity varies from 60 to $75 \%$ (Muhuyi et al., 1999).
A detailed description of herd management has been reported by Muhuyi et al., (1999). Briefly, the calves are immediately removed from their dams at birth, weighed and ear tagged. They are bucket fed, receiving colostrum in the first 4 days, and whole milk for about 9 weeks. Heifers and dry cows are managed separately in a dry herd and introduced into the milking herd 1 month before calving. Lactating cows are grazed on the best pastures with no supplementation and hand milked twice daily in mobile milking parlours. Water is provided ad libitum and mineral licks are provided when they are available. Cows with bad temper leading to difficult milking are culled.

\section{Data characteristics}

TD records from the first three lactations of Sahiwal cows at the NSS obtained from 1978 to 2002 were used in this study. First TD comprised of daily yield records sampled between days 2 and 15 post partum, while the second TD was comprised daily yield sampled between days 16 and 31. Time interval between successive tests was approximately 30 days. Daily milk yield record was calculated as the sum of milk recorded in the morning and evening. Because of the considerable short lactation length in $B$. indicus cattle (usually less than 280 days) a maximum of eight TDs were allowed. Characteristics of the data used in this study are presented in Table 1. Milk records of animals receiving special treatment were not included e.g. cows under training for livestock exhibitions and shows, and records of cows used in feeding experiments. Animals whose lactation was terminated by death, sale or due to bad temper and difficult milking were also removed. Lactations initiated as a result of abortions were also eliminated.

The final analysis consisted of cows that had at least the first TD record. Records on lactation yield were obtained for cows with at least the first four TD milk records. In this case, $81 \%$ of cows in the analysis had at least the first four TD records. Lactation yield for each cow was extracted from available milk records. Lactation yield is usually calculated as the sum of daily milk yield a cow produces in a particular lactation. No restrictions were imposed on the minimum TD and lactation length because of the considerable variation in lactation length and daily milk yield in B. indicus breeds (Madalena, 1988; Maule, 1990; Rege et al., 1992; Dahlin et al., 1998). As a result, the number of TD records were variable throughout the eight TD (Table 1). A total of 19376 daily yield records from the first three lactations of 1618 cows daughters of 162 sires were used to make inferences on genetic and phenotypic parameters.

\section{Statistical analyses}

Variance components were estimated using univariate and multivariate TDM. All runs were carried out using the DFREML software package (Meyer, 1989). Animal models were used throughout, incorporating all the pedigree information available. Table 2 shows the structure 
Table 1 Number of and percent missing records, average days in milk (DIM) and daily yield records in each test day (TD) and in the first three lactations and distribution of records in the fixed effects

\begin{tabular}{|c|c|c|c|c|c|c|c|c|c|c|c|}
\hline & \multicolumn{8}{|c|}{ TD } & \multicolumn{3}{|c|}{ Lactation } \\
\hline & 1 & 2 & 3 & 4 & 5 & 6 & 7 & 8 & 1 & 2 & 3 \\
\hline No. of records & 3260 & 2678 & 2330 & 2330 & 2397 & 2194 & 2016 & 2171 & 8404 & 6448 & 4524 \\
\hline DIM & 7 & 23 & 53 & 83 & 117 & 147 & 178 & 212 & - & - & - \\
\hline$\%$ missing records ${ }^{\dagger}$ & 0 & 17.8 & 28.5 & 28.5 & 26.4 & 32.7 & 38.1 & 33.3 & 0 & 23.3 & 46 \\
\hline Milk yield & 6 & 6.4 & 5.6 & 4.8 & 4.2 & 3.7 & 3.4 & 3 & 4.4 & 5 & 5 \\
\hline s.d. & 2.5 & 2.6 & 2.5 & 2.3 & 2.1 & 1.9 & 1.8 & 1.6 & 2.3 & 2.7 & 2.7 \\
\hline Minimum & 0.5 & 0.5 & 0.5 & 0.5 & 0.5 & 0.5 & 0.5 & 0.5 & 0.5 & 0.5 & 0.5 \\
\hline Maximum & 17 & 17 & 14.5 & 14.5 & 12 & 10.5 & 10.5 & 11.5 & 14.5 & 14.5 & 17 \\
\hline \multicolumn{12}{|l|}{ Season } \\
\hline 1 & 681 & 593 & 552 & 608 & 610 & 509 & 498 & 557 & 2011 & 1518 & 1079 \\
\hline 2 & 882 & 738 & 562 & 494 & 536 & 539 & 530 & 531 & 2049 & 1645 & 1118 \\
\hline 3 & 876 & 698 & 681 & 651 & 639 & 526 & 432 & 507 & 2173 & 1684 & 1153 \\
\hline 4 & 821 & 649 & 535 & 577 & 612 & 620 & 556 & 576 & 2171 & 1601 & 1174 \\
\hline \multicolumn{12}{|l|}{ Lactation } \\
\hline 1 & 1376 & 1176 & 1015 & 1018 & 1041 & 952 & 873 & 953 & & & \\
\hline 2 & 1110 & 880 & 766 & 764 & 789 & 738 & 673 & 728 & & & \\
\hline 3 & 774 & 622 & 549 & 548 & 567 & 504 & 470 & 490 & & & \\
\hline \multicolumn{12}{|l|}{ Age class } \\
\hline 1 & 201 & 177 & 153 & 155 & 165 & 150 & 139 & 142 & 1277 & 5 & \\
\hline 2 & 586 & 510 & 432 & 433 & 443 & 412 & 382 & 410 & 3511 & 94 & 3 \\
\hline 3 & 876 & 714 & 618 & 624 & 620 & 579 & 526 & 576 & 2778 & 2319 & 36 \\
\hline 4 & 642 & 510 & 436 & 428 & 457 & 403 & 368 & 411 & 753 & 2123 & 779 \\
\hline 5 & 492 & 390 & 355 & 350 & 360 & 331 & 303 & 318 & 82 & 1369 & 1448 \\
\hline 6 & 275 & 215 & 197 & 201 & 207 & 185 & 171 & 180 & 3 & 389 & 1239 \\
\hline 7 & 138 & 117 & 104 & 105 & 105 & 99 & 92 & 97 & & 113 & 744 \\
\hline 8 & 50 & 45 & 35 & 34 & 40 & 35 & 35 & 37 & & 36 & 275 \\
\hline
\end{tabular}

${ }^{\dagger}$ Relative to first TD and lactation yield.

of the pedigree. Mixed model equations in the analyses were solved iteratively and the simplex procedure was used to locate the maximum of the log-likelihood function. Analyses were terminated when the change in variance of function values (-2log likelihood) fell below $10^{-5}$. Variance components were estimated based on two different definitions of contemporary group (CG). Contemporary groups were defined either based on the year-season of calving (YSCV) or on the year-season of TD milk sampling (YSTD).
Data were analysed using seven different models. Model 1 was a multivariate repeatability model that was an extension of the repeatability TD model proposed by Ptak and Schaeffer (1993). In this case, daily milk yield records within lactation were considered as repeated traits and the three lactations treated as separate traits (Reents et al., 1995a and b; Rekaya et al., 1999). The shape of the lactation curve was accounted for by fixed regression of yield on days in milk (DIM), while the additive genetic effect of the animal was modelled as a constant for each DIM.

Table 2 Pedigree structure

\begin{tabular}{|c|c|c|c|c|c|c|c|c|}
\hline & \multicolumn{8}{|c|}{ Test day } \\
\hline & 1 & 2 & 3 & 4 & 5 & 6 & 7 & 8 \\
\hline No. of cows with records & 1619 & 1425 & 1310 & 1310 & 1319 & 1251 & 1190 & 1241 \\
\hline No. of sires in the pedigree & 319 & 319 & 319 & 319 & 319 & 319 & 319 & 319 \\
\hline No. of sires with progeny records & 168 & 160 & 156 & 156 & 156 & 151 & 148 & 148 \\
\hline No. of grand sires with progeny records & 145 & 140 & 133 & 133 & 133 & 119 & 114 & 120 \\
\hline Average no. of progeny per sire & 9.6 & 8.9 & 8.4 & 8.4 & 8.5 & 8.3 & 8.0 & 8.4 \\
\hline No. of dams in pedigree & 1857 & 1857 & 1857 & 1857 & 1857 & 1857 & 1857 & 1857 \\
\hline No. of dams with progeny records & 862 & 798 & 752 & 752 & 752 & 724 & 699 & 722 \\
\hline No. of grand dams with progeny records & 432 & 421 & 413 & 413 & 413 & 399 & 387 & 397 \\
\hline Average no. of progeny per dam & 2.0 & 1.8 & 1.7 & 1.7 & 1.8 & 1.6 & 1.5 & 1.6 \\
\hline
\end{tabular}


The covariances between the residuals were assumed to be zero. Model 1 was represented as follows:

$$
\begin{aligned}
y_{i j k l m}= & \mu+C_{i m}+a_{j}+b\left(D_{j} M_{k l m}\right) \\
& +b^{2}\left(D_{I M} M_{k l m}\right)+g_{k m}+p_{k m}+e_{i j k l m}
\end{aligned}
$$

where $y_{i j k l m}$ is the daily milk yield record in animal $k_{1}$ in lactation $m(m=1,2,3)$ and TD $I(I=1, \ldots, 8), \mu$ is the mean daily milk yield for cows in lactation $m, C G_{i m}$ is the effect of contemporary group $i$ for cows in lactation $m$, defined as YSCV, age $e_{j}$ is the fixed effect of age class $j$ $(j=1, \ldots, 8), b$ and $b^{2}$ are the linear and quadratic effect of DIM in animal $k$ and lactation $m$ on TD $I$, respectively, $g_{k m}$ is the additive genetic effect of animal $k$ in lactation $m, p_{k m}$ is the permanent environmental effect of animal $k$ in lactation $m$ and $e_{i j k l m}$ is the residual term. The year of calving or of TD sampling were from 1978 to 2002 each with four seasons: January to March for the first dry season; April to June for the main wet season; July to September and October to December as the secondary dry and wet seasons, respectively. Age at calving was grouped into eight classes as: 30 to 39 months, 40 to 49 months, 50 to 59 months, 60 to 69 months, 70 to 79 months, 80 to 89 months, 90 to 99 months and $>100$ months. Distribution of records in these fixed effects is shown in Table 1.

Model 2 was similar to model 1 but CGs were defined based on YSTD sampling. Models 3 and 4 were univariate repeatability models and the effects fitted similar to models 1 and 2, respectively. However, these effects were fitted within lactation. Model 5 was a multitrait TDM and included eight TD within each lactation which were considered as separate traits. The effects fitted in model 5 were similar to those fitted in model 2 but the permanent environmental effect of animal was not included. Model 6 was similar to model 5 and in this case, daily milk yield in the three lactations were pooled together and treated as repeated measures in each lactation. This allowed for a permanent environmental effect to be fitted. Model 7 was bivariate and was used to estimate genetic and phenotypic correlations between daily milk and lactation yield in the first three lactations. The effects fitted for daily milk yield were similar to those fitted in model 2 but the permanent environmental effects were ignored. For milk yield in each lactation, the fixed effects fitted included YSCV and age at calving.

In the analyses the covariances of the three random effects were zero and levels of each were independently distributed with variances $\sigma_{a}^{2}$ for animal, $\sigma_{p}^{2}$ for permanent environmental effects, and $\sigma_{\mathrm{e}}^{2}$ for residuals.

\section{Results and discussion}

Genetic and phenotypic parameters under different alternatives of $C G$

Table 3 shows the estimates of variance components and of heritability, repeatability and genetic and phenotypic
Table 3 Additive genetic $\left(\sigma_{a}^{2}\right)$, permanent environmental $\left(\sigma_{\text {pe }}^{2}\right)$ and residual $\left(\sigma_{e}^{2}\right)$ variances, heritability $\left(\mathrm{h}^{2}\right)$, genetic and phenotypic correlation and repeatability $(\mathrm{r})$ in the first three lactations under

\begin{tabular}{|c|c|c|c|c|c|c|c|c|}
\hline \multirow[b]{2}{*}{ Model $^{\dagger}$} & \multirow[b]{2}{*}{ Lactation } & \multicolumn{3}{|c|}{ Component } & \multicolumn{3}{|c|}{ Lactation $^{\ddagger}$} & \multirow[b]{2}{*}{$r$} \\
\hline & & $\sigma_{a}^{2}$ & $\sigma_{\mathrm{pe}}^{2}$ & $\sigma_{\mathrm{e}}^{2}$ & 1 & 2 & 3 & \\
\hline \multirow[t]{3}{*}{1} & 1 & 0.78 & 1.32 & 1.86 & 0.20 & 0.63 & 0.66 & 0.53 \\
\hline & 2 & 0.77 & 1.65 & 1.95 & 0.27 & 0.18 & 0.53 & 0.55 \\
\hline & 3 & 0.94 & 1.39 & 2.11 & 0.24 & 0.30 & 0.20 & 0.54 \\
\hline \multirow[t]{3}{*}{2} & 1 & 0.85 & 1.40 & 1.68 & 0.22 & 0.60 & 0.61 & 0.58 \\
\hline & 2 & 1.32 & 1.45 & 1.67 & 0.29 & 0.30 & 0.61 & 0.52 \\
\hline & 3 & 0.97 & 1.63 & 1.83 & 0.27 & 0.37 & 0.22 & 0.59 \\
\hline
\end{tabular}
models 1 and 2

${ }^{\dagger}$ See text for description of models.

${ }^{\ddagger}$ Heritabilities (diagonal), genetic (above diagonal) and phenotypic (below diagonal) correlations. Standard errors for heritability estimates and genetic correlations ranged from 0.04 to 0.06 and from 0.10 to 0.14 in both models, respectively.

correlations from models 1 and 2 . The estimates of variance components and of heritability and repeatability from models 3 and 4 are shown in Table 4. Additive genetic and permanent environmental variances were higher in model 2 than model 1. This implies that detection of differences among animals, both at genetic and environmental levels, is enhanced by assigning cows to year-season of TD milk sampling than to year-season of calving. The residual variances were lower in models 2 and 4 than models 1 and 3 . This indicates that more environmental variation is removed by comparing cows based on the TD sampling than on the period of calving. Similar findings have also been reported in the Holstein-Friesian cattle (Rekaya et al., 1999). Studies on variance components and genetic parameter estimates based on TDM for the Sahiwal cattle breed are scarce in the literature. A comparison of residual variances between lactations showed that they were highest in the third lactation in models 1 and 2 (Table 3) and models 3 and 4 (Table 4). The large residual variance associated with the third lactation could be due to changes in the mean lactation milk yield and other sources of variation not accounted for in the models such as length of the dry and gestation periods influencing subsequent lactations. Increased residual variance in later lactations has

Table 4 Additive genetic $\left(\sigma_{a}^{2}\right)$, permanent environmental $\left(\sigma_{\text {pe }}^{2}\right)$ and residual $\left(\sigma_{\mathrm{e}}^{2}\right)$ variances, heritability $\left(\mathrm{h}^{2}\right)$ and repeatability $(\mathrm{r})$ in the first three lactations under models 3 and $4^{\dagger}$

\begin{tabular}{lcccccc}
\hline \hline Model & Lactation & $\sigma_{\mathrm{a}}^{2}$ & $\sigma_{\mathrm{pe}}^{2}$ & $\sigma_{\mathrm{e}}^{2}$ & $h^{2}$ & $r$ \\
\hline 3 & 1 & 0.67 & 2.14 & 1.79 & 0.15 & 0.61 \\
& 2 & 0.62 & 2.40 & 1.94 & 0.13 & 0.60 \\
& 3 & 0.35 & 2.36 & 2.03 & 0.07 & 0.56 \\
4 & 1 & 0.78 & 2.02 & 1.62 & 0.18 & 0.64 \\
& 2 & 0.72 & 2.46 & 1.68 & 0.15 & 0.66 \\
& 3 & 0.44 & 2.44 & 1.83 & 0.09 & 0.61 \\
\hline \hline
\end{tabular}

${ }^{\dagger}$ Standard errors for heritability estimates ranged from 0.04 to 0.05 in both models. See text for description of models. 
also been reported (Teepker and Swalve, 1988; Rekaya et al., 1999).

The estimates of heritability were higher in models 2 and 4 than in models 1 and 3 . This was attributed to a proportionally large increase in the additive genetic variance with a corresponding reduction in the residual variance in models 2 and 4 . Heritability estimates obtained in model 2 are within the range of estimates obtained for TD in Holstein-Friesian (Rekaya et al., 1999). Apart from lactation one and three, repeatability estimates were higher in model 2 (Table 3) and model 4 (Table 4). Repeatability estimate in the present study were comparable with those reported by Lidauer et al., (2003). Genetic correlations were moderately high in models 1 and 2 (Table 3) while phenotypic correlations were correspondingly lower than genetic correlations. Genetic correlations were higher between lactation one and three in models 1 and 2 than between lactations one and two. On the contrary, phenotypic correlations were higher between adjacent lactations than non-adjacent ones. Similar trends in the genetic and phenotypic correlation estimates between lactations have been reported by Rekaya et al. (1999) in the Holstein-Friesian population in Spain.

Genetic and phenotypic parameters in each lactation and in the pooled lactations

The additive genetic and residual variances of daily milk yield in the first three lactations and in the pooled data set estimated using models 5 and 6 , respectively are shown in Table 5. In all lactations, there was an increase in the additive genetic variance from TD 1 to TD 2. Thereafter, there was a general reduction but only in lactation 1 and 2 . In the pooled lactations, there was a gradual reduction in the additive genetic variance from TD 1 to TD 8. This pattern in additive genetic variance is similar to that reported in the literature for cattle (Kettunen et al., 1998; Olori et al., 1999; Rekaya et al., 1999). The residual variances were highest in TD 1 in all lactations. This could possibly be due

Table 5 Additive genetic $\left(\sigma_{a}^{2}\right)$ and residual variances $\left(\sigma_{\mathrm{e}}^{2}\right)$ of daily yield in the first three lactations and in the pooled lactations ${ }^{+}$

\begin{tabular}{|c|c|c|c|c|c|c|c|c|}
\hline \multirow[b]{3}{*}{$\mathrm{TD}^{\ddagger}$} & \multicolumn{6}{|c|}{ Lactation } & & \\
\hline & \multicolumn{2}{|c|}{1} & \multicolumn{2}{|c|}{2} & \multicolumn{2}{|c|}{3} & \multicolumn{2}{|c|}{ Pooled } \\
\hline & $\sigma_{\mathrm{a}}^{2}$ & $\sigma_{\mathrm{e}}^{2}$ & $\sigma_{\mathrm{a}}^{2}$ & $\sigma_{\mathrm{e}}^{2}$ & $\sigma_{\mathrm{a}}^{2}$ & $\sigma_{\mathrm{e}}^{2}$ & $\sigma_{\mathrm{a}}^{2}$ & $\sigma_{\mathrm{e}}^{2}$ \\
\hline 1 & 1.55 & 2.57 & 1.88 & 2.70 & 1.76 & 2.69 & 1.76 & 2.85 \\
\hline 2 & 1.64 & 2.10 & 2.20 & 2.03 & 2.08 & 2.20 & 1.70 & 2.67 \\
\hline 3 & 1.46 & 1.69 & 1.98 & 1.80 & 1.24 & 2.45 & 1.60 & 2.41 \\
\hline 4 & 1.41 & 1.85 & 1.49 & 1.52 & 2.00 & 1.62 & 1.50 & 2.26 \\
\hline 5 & 0.75 & 1.94 & 1.35 & 1.37 & 1.73 & 1.62 & 1.40 & 2.21 \\
\hline 6 & 1.02 & 1.68 & 1.03 & 1.68 & 1.73 & 1.58 & 1.35 & 2.19 \\
\hline 7 & 0.76 & 1.79 & 1.08 & 1.28 & 1.18 & 1.30 & 1.20 & 2.13 \\
\hline 8 & 0.96 & 1.57 & 1.00 & 1.55 & 1.44 & 1.20 & 1.19 & 1.46 \\
\hline
\end{tabular}

${ }^{\dagger}$ The additive genetic and residual variances of daily milk yield in the first three lactations and in the pooled data set were estimated using models 5 and 6 , respectively. See text for description of models.

${ }^{\ddagger} \mathrm{TD}=$ test day. to uncontrolled environmental effects at the start of lactation and problems associated with milk let down in the absence of the calf in $B$. indicus breeds especially in the early stages of lactation. Consistent with other studies (e.g. Swalve, 1995; Pool et al., 2000; Druet et al., 2003), there was generally a reduction in residual variances with increase in TD number both within and pooled lactations.

Heritabilities of, and genetic and phenotypic correlations between daily milk yield in the first three lactations and in the pooled data set estimated using models 5 and 6, respectively are shown in Table 6 . Heritability estimates ranged from 0.28 to $0.46,0.38$ to 0.52 and 0.33 to 0.52 for daily milk yield in the first, second and third lactation, respectively and from 0.25 to 0.30 for the pooled data set. An increase in the residual variance for TD 3 in the third lactation resulted in a substantially lower heritability estimate compared with TD 2 and 4. The third TD corresponds to approximately 2 months after calving. The increased residual variance could be attributed to physiological imbalances associated with peak milk yield in advanced parities at this period. Furthermore, most cows resume their oestrous cycling at around this period which could also affect daily yield. Therefore, variations in daily milk yield resulting from such phenomena would be apportioned to the residual term. Heritability estimates were lower considering the pooled lactations (Table 6). Heritability estimates in lactation 1 in the present study are within the range of 0.28 to 0.48 reported for British-Holsteins (Pander et al., 1992). Estimates in lactation 2 and 3 fall within the range of estimates obtained using random regression TD models (Jamrozik and Schaeffer, 1997; Kettunen et al., 1998). In those studies, heritability estimates ranged from 0.40 to 0.59 (Jamrozik and Schaeffer, 1997) and 0.41 to 0.58 (Kettunen et al., 1998).

A comparison of heritability estimates between lactations showed that they were lowest in the first lactation. Low heritability estimates for first lactation daily yield have been reported (Meyer et al., 1989; Machado et al., 1998). Heritability estimates in these studies ranged from 0.17 to 0.28 (Meyer et al., 1989) and from 0.04 to 0.32 (Machado et al., 1998). In the first and second lactation, the heritability estimates were highest between TD 2 and TD 4. It has been shown that estimates of heritability are higher in mid lactation than at the beginning and end of lactation (Rekaya et al., 1999; Lidauer et al., 2003). Heritability estimates were low but relatively stable across lactation in the pooled lactation except in TD 8 where the heritability increased due to reduction in the error variance (Table 5). These low heritability estimates are attributed to a rather high phenotypic variance as result of accounting for repeated TD measures across the three lactations. Heritability estimates from the pooled lactations were comparable with estimates from the model 2.

Genetic correlations among daily milk yields ranged from 0.41 to $0.93,0.50$ to 0.83 and 0.43 to 0.86 in the first, second and third lactation, respectively and from 0.34 to 0.68 in the pooled data set (Table 6). The phenotypic 
Table 6 Heritabilities (along diagonal) ${ }^{\dagger}$, genetic (above diagonal) ${ }^{\dagger}$ and phenotypic (below diagonal) correlations between daily yield in the first three lactations and in the pooled lactations ${ }^{\neq}$

\begin{tabular}{|c|c|c|c|c|c|c|c|c|}
\hline \multirow[b]{2}{*}{ TD } & \multicolumn{8}{|c|}{ TD } \\
\hline & 1 & 2 & 3 & 4 & 5 & 6 & 7 & 8 \\
\hline \multicolumn{9}{|c|}{ Lactation 1} \\
\hline 1 & 0.38 & 0.63 & 0.53 & 0.55 & 0.47 & 0.49 & 0.60 & 0.41 \\
\hline 2 & 0.25 & 0.44 & 0.64 & 0.62 & 0.66 & 0.57 & 0.61 & 0.45 \\
\hline 3 & 0.22 & 0.29 & 0.46 & 0.63 & 0.69 & 0.57 & 0.60 & 0.43 \\
\hline 4 & 0.22 & 0.27 & 0.28 & 0.43 & 0.85 & 0.69 & 0.72 & 0.58 \\
\hline 5 & 0.15 & 0.23 & 0.25 & 0.30 & 0.28 & 0.65 & 0.71 & 0.66 \\
\hline 6 & 0.18 & 0.23 & 0.23 & 0.28 & 0.21 & 0.38 & 0.92 & 0.93 \\
\hline 7 & 0.20 & 0.20 & 0.22 & 0.26 & 0.21 & 0.31 & 0.30 & 0.73 \\
\hline 8 & 0.18 & 0.20 & 0.20 & 0.26 & 0.24 & 0.31 & 0.28 & 0.38 \\
\hline \multicolumn{9}{|c|}{ Lactation 2} \\
\hline 1 & 0.41 & 0.65 & 0.56 & 0.53 & 0.52 & 0.65 & 0.58 & 0.50 \\
\hline 2 & 0.30 & 0.52 & 0.67 & 0.63 & 0.65 & 0.70 & 0.61 & 0.63 \\
\hline 3 & 0.26 & 0.35 & 0.52 & 0.52 & 0.84 & 0.72 & 0.80 & 0.70 \\
\hline 4 & 0.24 & 0.32 & 0.27 & 0.49 & 0.62 & 0.77 & 0.62 & 0.56 \\
\hline 5 & 0.23 & 0.33 & 0.43 & 0.31 & 0.49 & 0.78 & 0.79 & 0.83 \\
\hline 6 & 0.32 & 0.39 & 0.40 & 0.41 & 0.43 & 0.38 & 0.84 & 0.73 \\
\hline 7 & 0.25 & 0.30 & 0.39 & 0.30 & 0.38 & 0.44 & 0.46 & 0.66 \\
\hline 8 & 0.20 & 0.28 & 0.32 & 0.24 & 0.37 & 0.36 & 0.28 & 0.39 \\
\hline \multicolumn{9}{|c|}{ Lactation 3} \\
\hline 1 & 0.40 & 0.65 & 0.68 & 0.66 & 043 & 0.50 & 0.79 & 0.50 \\
\hline 2 & 0.29 & 0.49 & 0.77 & 0.69 & 0.50 & 0.53 & 0.83 & 0.53 \\
\hline 3 & 0.24 & 0.31 & 0.33 & 0.63 & 0.70 & 0.66 & 0.86 & 0.79 \\
\hline 4 & 0.31 & 0.37 & 0.28 & 0.51 & 0.58 & 0.61 & 0.78 & 0.58 \\
\hline 5 & 0.25 & 0.32 & 0.37 & 0.41 & 0.52 & 0.63 & 0.57 & 0.70 \\
\hline 6 & 0.24 & 0.28 & 0.29 & 0.36 & 0.44 & 0.52 & 0.65 & 0.57 \\
\hline 7 & 0.34 & 0.40 & 0.34 & 0.42 & 0.36 & 0.34 & 0.48 & 0.79 \\
\hline 8 & 0.23 & 0.27 & 0.34 & 0.33 & 0.48 & 0.31 & 0.40 & 0.54 \\
\hline \multicolumn{9}{|c|}{ Pooled } \\
\hline 1 & 0.27 & 0.50 & 0.45 & 0.40 & 0.44 & 0.50 & 0.41 & 0.34 \\
\hline 2 & 0.37 & 0.26 & 0.55 & 0.47 & 0.55 & 0.56 & 0.45 & 0.45 \\
\hline 3 & 0.37 & 0.41 & 0.26 & 0.57 & 0.51 & 0.59 & 0.61 & 0.61 \\
\hline 4 & 0.35 & 0.32 & 0.41 & 0.26 & 0.57 & 0.53 & 0.50 & 0.50 \\
\hline 5 & 0.35 & 0.35 & 0.40 & 0.41 & 0.25 & 0.60 & 0.55 & 0.52 \\
\hline 6 & 0.38 & 0.36 & 0.43 & 0.41 & 0.43 & 0.27 & 0.65 & 0.57 \\
\hline 7 & 0.36 & 0.33 & 0.44 & 0.40 & 0.42 & 0.46 & 0.25 & 0.68 \\
\hline 8 & 0.36 & 0.36 & 0.47 & 0.43 & 0.44 & 0.47 & 0.50 & 0.30 \\
\hline
\end{tabular}

${ }^{\dagger}$ Standard errors for heritability estimates and genetic correlations ranged from 0.06 to 0.17 and from 0.06 to 0.18 , respectively.

${ }^{\ddagger} H$ Heritabilities of, and genetic and phenotypic correlations between daily milk yield in the first three lactations and in the pooled data were estimated using models 5 and 6 , respectively. See text for description of models. TD $=$ test day.

correlations were correspondingly lower. The genetic correlations estimated in this study were lower than those reported in the literature (e.g. Pander et al., 1992; Jamrozik and Schaeffer, 1997; Vargas et al., 1998) but within the ranges of 0.38 to 0.97 and 0.34 to 0.99 reported by Kettunen et al. (1998) and Druet et al. (2003), respectively. Contrary to studies elsewhere (Jamrozik and Schaeffer, 1997; Rekaya et al., 1999; Druet et al., 2003), there was no tendency of genetic and phenotypic correlations to decrease as the distance between TD increased. In this study, correlation estimates were not always consistent both when considering each lactation and the pooled lactation. For example, the genetic correlation between TD 1 and TD 3 (0.53) was lower compared with the genetic correlation between TD 1 and TD $7(0.60)$ in the first lactation. The observed inconsistence in genetic correlation could be attributed to the variation in number of daily yield records in each TD (Table 1). Furthermore, definition of the TD milk yield, interval between TD records, and environment and other management factors were different between the present study and the other studies. Inconsistency in genetic and phenotypic correlations among TD has also been reported elsewhere (Pander et al., 1992; Vargas et al., 1998).

When making decisions on how daily milk yield records could be used in genetic evaluation, it must be decided whether these measurements are repeated records or are observations on different uncorrelated traits (Swalve, 2000). Univariate repeatability model could be used if genetic correlations among daily yield records are consistently close to unit and where computational resources are a constraint. It is clear that genetic correlations in this study differ from unity, both within lactation and in the pooled data set. Therefore, a multiple trait model should ideally be used for genetic evaluation of the Sahiwal cattle breeding programme.

Relationship between daily milk yield and lactation yield Table 7 shows the genetic and phenotypic correlations between daily yield and lactation yield in the first three lactations. Genetic and phenotypic correlations were high and positive in the three lactations. Genetic correlations ranged from 0.84 to $0.99,0.94$ to 1.00 and 0.94 to 0.97 in the first, second and third lactations, respectively. Phenotypic correlations were also high ranging from 0.50 to 0.85 , 0.50 to 0.83 and 0.53 to 0.87 in the first, second and third lactations, respectively. The estimates in this study were consistent with estimates from literature (Meyer et al., 1989; Pander et al., 1992; Kettunen et al., 1998). The high

Table 7 Genetic $\left(r_{\mathrm{a}}\right)$ and phenotypic $\left(\mathrm{r}_{\mathrm{p}}\right)$ correlations between lactation yield and daily yield in the first three lactations estimated using model $7^{+}$

\begin{tabular}{|c|c|c|c|c|c|c|}
\hline \multirow[b]{3}{*}{$\mathrm{TD}^{\ddagger}$} & \multicolumn{6}{|c|}{ Lactation } \\
\hline & \multicolumn{2}{|c|}{1} & \multicolumn{2}{|c|}{2} & \multicolumn{2}{|c|}{3} \\
\hline & $r_{\mathrm{g}}$ & $r_{p}$ & $r_{\mathrm{g}}$ & $r_{\mathrm{p}}$ & $r_{g}$ & $r_{\mathrm{p}}$ \\
\hline 1 & 0.89 & 0.50 & 1.00 & 0.50 & 0.94 & 0.53 \\
\hline 2 & 0.91 & 0.79 & 0.94 & 0.65 & 0.96 & 0.66 \\
\hline 3 & 0.99 & 0.84 & 0.96 & 0.78 & 0.94 & 0.74 \\
\hline 4 & 0.99 & 0.79 & 0.97 & 0.83 & 0.96 & 0.80 \\
\hline 5 & 0.84 & 0.76 & 0.94 & 0.83 & 0.96 & 0.76 \\
\hline 6 & 0.98 & 0.84 & 0.98 & 0.82 & 0.94 & 0.83 \\
\hline 7 & 0.98 & 0.85 & 0.98 & 0.83 & 0.97 & 0.87 \\
\hline 8 & 0.97 & 0.79 & 0.98 & 0.83 & 0.96 & 0.84 \\
\hline
\end{tabular}

${ }^{\ddagger}$ Standard errors ranged from 0.06 to 0.13 . See text for description of model 7.

${ }^{\ddagger} \mathrm{TD}=$ test day. 
genetic correlation between daily yield and lactation yield imply that both traits could genetically be considered as expression of the same trait. Therefore, increased lactation yield could be achieved by simply selecting animals with high daily yield at a particular TD.

Genetic evaluation based on daily yield data are robust because they consider both genetic and environmental factors that are unique to a particular TD, which gradually and continuously change over the lactation period (Ptak and Schaeffer, 1993; Van der Werf et al., 1998; Rekaya et al., 1999). Since, information on daily milk yield is not dependent on lactation length, inherent biases arising from culling of heifers before completion of lactation are eliminated (Pander et al., 1992). Daily milk yield records provide a substantial amount of data compared with complete lactation within the interval of evaluation thus improving on the accuracy of cow evaluation (Strabel and Szwaczkowski, 1997; Rekaya et al., 1999; Misztal et al., 2000). Even for completed lactations, selection on a properly weighted index of TD records could be more accurate than selecting based on phenotypic records of total lactation production (Pander et al., 1992). With improved statistical methods associated with TD models, both genetic and environmental effects associated with each TD are better accounted for (Rekaya et al., 1999; Schaeffer et al., 2000). This gives a more precise definition of the $C G$, and allows more accurate description of stage of lactation which would be difficult to model with models based on standardised lactation yield (Meyer et al., 1989; Ptak and Schaeffer, 1993; Visscher and Goddard, 1995).

In estimation of genetic and phenotypic parameters, the emphasis should be on making use of large data sets to enhance accuracy of estimation. In this study, however limited numbers of records were used to estimate genetic and phenotypic parameters because of the relatively small herd size. Furthermore, most dairy cattle enterprises in Kenya and other countries in the tropics are usually characterised by inefficient and poor field recording (Syrstad and Ruane, 1998; Kahi et al., 2004). Therefore, it is very difficult to obtain relatively large data sets to enhance accuracy in genetic and phenotypic parameters estimation as is the case in the developed countries. However, in future, genetic evaluation could be based on relatively large data size as more records are collected from NSS and other Sahiwal cattle herds in Kenya. This would increase the accuracy and reliability of genetic and phenotypic parameters based on TDM. The fixed regression TDM used in this study do not account for individual differences in lactation curve. Therefore, there is need for further research to explore the use of random regression models in genetic evaluation of $B$. indicus dairy cattle. Random regression models are more robust because individual genetic variation in the coarse of the lactation can be estimated and breeding values can be presented in the form of lactation curve or persistence which would provide supplementary information when making selection decisions (Jamrozik and Schaeffer, 1997).

\section{Conclusions}

In this study, genetic and phenotypic parameters were estimated for daily milk yield based on various fixed regression TDM. Variance components were influenced by CG which resulted in differences in heritability and repeatability estimates between models. Models fitting YSTD instead of YSCV were found to be superior since they led to reduction in the residual variances and an increase in the additive genetic variances. The study has also demonstrated the potential use of daily yield in genetic evaluation programmes for the Sahiwal cattle breed. This is particularly desirable in production systems constrained by lack of the necessary infrastructure for proper milk recording as is the case in Kenya. Evaluation based on daily milk yield would offer a solution to handle such situations since it is least costly because only a few data points would be recorded per lactation.

\section{Acknowledgements}

We are greatly indebted to the Agricultural Research Fund (ARF) for financial support and Egerton University, Njoro, Kenya and the Kenya Agricultural Research Institute (KARI) Naivasha for provision of facilities.

\section{References}

Dahlin A, Khan UN, Zafar AH, Saleem M, Chaundhry MA and Philipsson J 1998. Genetic and environmental causes of variation in milk production traits of Sahiwal cattle in Pakistan. Animal Science 66, 307-318.

Druet $T$, Jaffrezic F, Boichard D and Ducroq V 2003. Modeling lactation curves and estimation of genetic parameters for first lactation test-day records of French Holstein cows. Journal of Dairy Science 86, 2480-2490.

Jamrozik J and Schaeffer LR 1997. Estimates of genetic parameters for a test day model with random regressions for yield traits of first lactation Holsteins. Journal of Dairy Science 80, 762-770.

Jensen J 2001. Genetic evaluation of dairy cattle using test day models. Journal of Dairy Science 84, 2803-2812.

Kahi AK, Nitter G and Gall CF 2004. Developing breeding schemes for pasture based dairy production systems in Kenya. II. Evaluation of alternative objectives and schemes using a two-tier open nucleus and young bull system. Livestock Production Science 88, 179-192.

Kahi AK, Thorpe W, Nitter G and Baker RL 2000. Crossbreeding for dairy production in the Lowland tropics of Kenya. I. Estimation of individual crossbreeding effects on milk production and reproductive traits and cow live weight. Livestock Production Science 63, 39-54.

Kettunen A, Mantysaari EA, Stranden I, Pösö J and Lidauer M 1998. Estimation of genetic parameters for first lactation test day milk production using random regression models. Proceedings of the sixth world congress on genetics applied to livestock production, 11-16 January, Armidale, NSW, Australia, vol. 23, pp. 307-310.

Khan UN, Dahlin A, Zafar AH, Saleem M, Chaudhry MA and Philipsson J 1999. Sahiwal cattle in Pakistan: genetic and environmental causes of variation in body weight and reproduction and their relationship to milk production. Animal Science 68, 97-108.

Lidauer M, Mantysaari EA and Stranden I 2003. Comparison of test day models for genetic evaluation of production traits in dairy cattle. Livestock Production Science 79, 73-86.

Machado SG, Freitas MAR and Gadini CH 1998. Genetic parameters of test day milk yield of Holstein cows. Proceedings of the sixth world congress on genetics applied to livestock production, 11-16 January, Armidale, NSW, vol. 21, pp. 427-430.

Madalena FE 1988. A note on the effect of variation of lactation length on the efficiency of tropical cattle selection for milk yield. Theoretical and Applied Genetics 76, 830-834. 
Maule JP 1990. The cattle of the Tropics. University of Edinburgh Centre for Tropical Veterinary Medicine, Edinburgh, UK.

Meyer K 1989. Restricted maximum likelihood to estimate variance component for animal models with several random effects using a derivative free algorithm. Genetics, Selection, Evolution 21, 318-327.

Meyer K, Grasser HU and Hammond K 1989. Estimation of genetic parameters for first lactation test day production of Australian black and white cows. Livestock Production Science 21, 177-199.

Misztal I, Strabel T, Jamrozik J, Mantysaari EA and Meuwissen THE 2000. Strategies for estimating the parameters needed for different test day models. Journal of Dairy Science 83, 1125-1134.

Muhuyi WB (1997) A comparison of the productivity of Kenya Sahiwal and their crosses in large scale dairy dual purpose and beef production systems. Ph.D. thesis, University of Nairobi, Kenya.

Muhuyi WB, Lokwaleput I and Sinkeet SN 1999. Conservation and utilisation of the Sahiwal cattle in Kenya. FAO Animal Genetics Research Information 26, 35-44.

Mwandotto BAJ 1994. Phenotypic, genetic and environmental parameter estimates of weight growth and maturing patterns in Sahiwal females. Bulletin of Animal Production 42, 61-67.

Olori VE, Hill WG, McGuirk BJ and Brotherstone S 1999. Estimating variance components for test day milk records by restricted maximum likelihood with a random regression animal model. Livestock Production Science 61, 53-63.

Pander BL, Hill WG and Thompson R 1992. Genetic parameters of test day records of British Holstein heifers. Animal Science 55, 11-21.

Ptak E and Schaeffer LR 1993. Use of test day yields for genetic evaluation of dairy sires and cows. Livestock Production Science 34, 23-34.

Pool MH, Janss LLG and Meuwissen THE 2000. Genetic parameters of Legendre polynomials for first lactation curves. Journal of Dairy Science 83, 2640-2649.

Reents R, Dekkers JCM and Schaeffer LR 1995a. Genetic evaluation of somatic cell score with multiple lactation test day model. Journal of Dairy Science 78, 2858-2870.

Reents R, Jamrozik J, Schaeffer LR and Dekkers JCM 1995b. Estimation of genetic parameters for test day somatic cell score. Journal of Dairy Science 78, 2847-2857.
Rege JEO, Lomole MA and Wakhungu JW 1992. An evaluation of a long-term breeding programme in a closed Sahiwal herd in Kenya. I. Effects of non-genetic factors on performance and genetic parameter estimates. Journal of Animal Breeding and Genetics 109, 364-373.

Rekaya R, Carabano MJ and Toro MA 1999. Use of test day yields for genetic evaluation of production traits of Holstein-Friesian cattle. Livestock Production Science 57, 203-217.

Schaeffer LR, Jamrozik J, Kistemaker GJ and Doormaal BJ 2000. Experience with a test day model. Journal of Dairy Science 83, 1135-1144.

Strabel T and Szwaczkowski T 1997. Additive and permanent environmental variance components for test day milk yields traits in Black-white cattle. Livestock Production Science 8, 91-98.

Swalve HH 1995. The effect of test day models on the estimation of genetic parameters and breeding values for dairy yield traits. Journal of Dairy Science 78, 929-938.

Swalve HH 2000. Theoretical basis and computation methods for different test day genetic evaluation methods. Journal of Dairy Science 83, 1115-1124.

Swalve HH 1998. Use of test day records for genetic evaluation. Proceedings of the sixth world congress of genetics applied to livestock production, 11-16 January, Armidale, NSW, Australia, vol. 23, pp. 301-302.

Syrstad 0 and Ruane J 1998. Prospects and Strategies for genetic improvement of the dairy potential of tropical cattle by selection. Tropical Animal Health and Production 30, 257-268.

Teepker G and Swalve HH 1988. Estimation of genetic parameters for milk production in the first three lactations. Livestock Production Science 20, 193-202.

Van der Werf JHJ, Goddard ME and Meyer K 1998. The use of covariance functions and random regression for genetic evaluation of milk production based on test day records. Journal of Dairy Science 81, 3300-3308.

Vargas B, Perez E and Van Arendonk JAM 1998. Analysis of test day yield data of Costa Rican dairy cattle. Journal of Dairy Science 81, 255-263.

Visscher PM and Goddard ME 1995. Genetic parameters for milk yield, survival, workability and type traits for Australian dairy cattle. Journal of Dairy Science 78, 205-220. 